\title{
Thermochemical stability of zirconia-titanium nitride as mixed ionic-electronic
} composites

Silva, P. S. M.; Esposito, V.; Marani, D.; Florio, D.Z. de ; Machado, I. F. ; Fonseca, F. C.

Published in:

Ceramics International

Link to article, DOI:

10.1016/j.ceramint.2018.02.039

Publication date:

2018

Document Version

Peer reviewed version

Link back to DTU Orbit

Citation (APA):

Silva, P. S. M., Esposito, V., Marani, D., Florio, D. Z. D., Machado, I. F., \& Fonseca, F. C. (2018).

Thermochemical stability of zirconia-titanium nitride as mixed ionic-electronic composites. Ceramics International, 44(7), 8440-8446. https://doi.org/10.1016/j.ceramint.2018.02.039

\section{General rights}

Copyright and moral rights for the publications made accessible in the public portal are retained by the authors and/or other copyright owners and it is a condition of accessing publications that users recognise and abide by the legal requirements associated with these rights.

- Users may download and print one copy of any publication from the public portal for the purpose of private study or research.

- You may not further distribute the material or use it for any profit-making activity or commercial gain

- You may freely distribute the URL identifying the publication in the public portal 


\section{Author's Accepted Manuscript}

Thermochemical stability of zirconia-titanium nitride as mixed ionic-electronic composites

P.S.M. Silva, V. Esposito, D. Marani, D.Z. de Florio, I.F. Machado, F.C. Fonseca

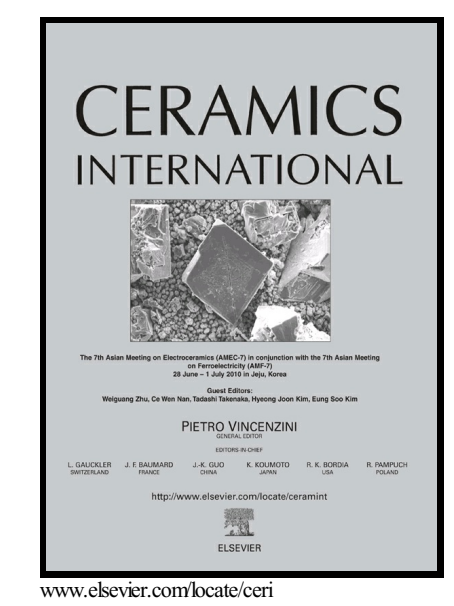

PII: $\quad$ S0272-8842(18)30340-7

DOI: $\quad$ https://doi.org/10.1016/j.ceramint.2018.02.039

Reference: CERI17441

To appear in: Ceramics International

Received date: 4 November 2017

Revised date: 15 January 2018

Accepted date: 4 February 2018

Cite this article as: P.S.M. Silva, V. Esposito, D. Marani, D.Z. de Florio, I.F. Machado and F.C. Fonseca, Thermochemical stability of zirconia-titanium nitride as mixed ionic-electronic composites, Ceramics International, https://doi.org/10.1016/j.ceramint.2018.02.039

This is a PDF file of an unedited manuscript that has been accepted for publication. As a service to our customers we are providing this early version of the manuscript. The manuscript will undergo copyediting, typesetting, and review of the resulting galley proof before it is published in its final citable form. Please note that during the production process errors may be discovered which could affect the content, and all legal disclaimers that apply to the journal pertain. 


\title{
ACCEPTED MANUSCRIPT
}

\section{Thermochemical stability of zirconia-titanium nitride as mixed ionic-electronic composites}

\author{
P. S. M. Silva ${ }^{1}$, V. Esposito ${ }^{2}$, D. Marani ${ }^{3}$, D. Z. de Florio ${ }^{3}$, I. F. Machado ${ }^{4}$, F. C. Fonseca ${ }^{1 *}$ \\ ${ }^{1}$ Instituto de Pesquisas Energéticas e Nucleares - IPEN-CNEN/SP, São Paulo, SP 05508-000,
}

\section{Brazil}

${ }^{2}$ Department of Energy Conversion and Storage, Technical University of Denmark, DK-4000

\section{Roskilde, Denmark}

${ }^{3}$ Universidade Federal do ABC, 09210-580 - Santo André, SP, Brazil

${ }^{4}$ Escola Politécnica, Universidade de São Paulo, 05508-900, São Paulo, SP, Brazil

*Corresponding author: fabiocf@usp.br

\begin{abstract}
Dense zirconia ( $8 \%$ molar yttria-stabilized $\mathrm{ZrO}_{2}$ )-titanium nitride (TiN) composites are fabricated to obtain mixed ionic-electronic conducting ceramic systems with high degree of electronic and thermal conductivity. The composites are consolidated by spark plasma sintering (SPS), starting from pure powders of the pristine phases mixed in different ratios $(\mathrm{TiN}=25,50,75 \mathrm{wt}$. \%). A careful optimization of the SPS conditions allows producing highly dense samples with no reaction between the phases or degradation by oxidation, thus maintaining the chemical integrity of the two phases. For all the composites, high electrical conductivity is attained. Samples exhibit metallic behavior, showing an unexpected percolation of TiN in the YSZ matrix for volume fraction $\leq 25$ wt.\% (27 vol.\%). Chemical degradation and electrical properties of the compounds were monitored under oxidative (air) and inert (Ar) atmosphere at high temperatures. The oxidation kinetics of the nitride phase was inhibited by the microstructure of the composite. The electrical properties of such
\end{abstract}




\section{ACCEPTED MANUSCRIPT}

composites were explored at high temperature to evaluate its application in electrochemical devices. As results, it is shown that electrical transport properties of the composite can be tuned by both the relative volume fraction of phases and controlled oxidative treatments. Adjusting such parameters different electric behaviors were observed ranging from predominant electronic conductors, to temperature-independent resistivity, and semiconducting.

Keywords: yttria-stabilized zirconia; TiN; Composite; spark plasma sintering; mixed ionicelectronic conductors

\section{Introduction}

Engineering advanced ceramic composites has become a key step to obtaining unprecedented materials properties. Such composites are increasingly important to the advancement of several strategic technologies, including structural components for harsh environments [1], energy [2], catalysis [3], and electronics [4]. Such advanced applications rely on properties that are rarely found in single-phase materials. The main idea in making advanced ceramic composites is, thus, achieving a synergy between functionalities and properties of the components. Some examples are matching lightness and/or microstructural properties of one ceramic with mechanical strength of another [5], as well as combining different electrochemical properties in one single material, [6,7]. Ceramic composites are often made of electro-ceramics, where electric, mechanical, thermal, properties are combined, attaining superior resistance to thermal or chemical stress at high temperatures and harsh environments [6-12]. This is the case of high temperature catalysis [13], gas separation membranes [14] and gas conversion reactors [15], where high mixed ionic-electronic conductivity (MIEC) is desired in order to achieve the suitable performances. 


\section{ACCEPTED MANUSCRIPT}

Metallic-like electrical conductivity is essential for decreasing ohmic losses in ceramic components. Delocalized electrons enhance thermal conduction which is crucial for a homogeneous temperature distribution, decreasing the likelihood of mechanical failure associated with thermal stress in ceramic components [8]. In this context, a large number of ceramic composites have been identified in recent years, combining excellent mechanical and electrical performances at high temperature [6-8,16-20]. Some composites exhibit functional properties superior to the single ceramic components, such as zero temperature coefficient (ZTC) of both thermal expansion and electrical/dielectric properties, machinability, etc. [16] Some examples of such remarkable composites materials are $\mathrm{ZrO}_{2} / \mathrm{WC}, \mathrm{Si}_{3} \mathrm{~N}_{4} / \mathrm{TiN}, \mathrm{ZrO}_{2} / \mathrm{TiN}$ and $\mathrm{Al}_{2} \mathrm{O}_{3} / \mathrm{TiC}$ [16]. Such composite materials can be machined [19] to complex shapes and replace conventional metal parts in many applications].

Among those composites, $\mathrm{ZrO}_{2} / \mathrm{TiN}$ shows remarkable performance at room temperature in terms of combination of electrical conductivity and mechanical properties [20-24]. Most of previous studies have focused on the mechanical properties of the stabilized- $\mathrm{ZrO}_{2} / \mathrm{TiN}$ composites. The addition of TiN increases both the fracture toughness and the hardness of the composite when compared to zirconia [20,24]. Additionally to the improved mechanical properties, an important goal of previous studies was to introduce a high electrical conductivity phase into the zirconia matrix to allow cost-effective fabrication by electrical discharge machining (EDM) [19]. The EDM allows complex and accurate shaping with good surface finish of components that avoids expensive mechanical grinding. Although the electrical properties of such composites had not been investigated in depth, the introduction of a high electrical conductivity into the stabilized-zirconia matrix is interesting for electrochemical applications where ionic conductivity and toughness of the zirconia component is combined with both high electronic and thermal conductivities of the TiN. Yttria stabilized-zirconia (YSZ) is the standard electrolyte in many applications ranging from 


\section{ACCEPTED MANUSCRIPT}

lambda sensors to solid oxide fuel cells (SOFCs) due to its relatively high oxygen ion conductivity. On the other hand, TiN has a strong metallic character resulting in very high electronic conductivity. TiN has excellent mechanical properties and is widely used as a surface coating in many applications [20,24]. However, while zirconia is a stable material in both reducing and oxidizing environments in a wide range of temperature, TiN undergoes chemical oxidation with formation of $\mathrm{TiO}_{2}$ at $\mathrm{T}>600{ }^{\circ} \mathrm{C}$ in air. The oxidation of $\mathrm{TiN}$ was reported to initiate from the formation of a $\mathrm{TiO}_{2}$ oxide surface layer [25-29]. Progressive oxygen diffusion promotes the formation of intermediate titanium oxy-nitride that progressively diffuses to the bulk with a rather slow kinetics controlled by diffusion of species through the oxide layer [25,29]. Thus, oxygen gradually substitutes nitrogen which in turn, is released in the molecular form from interstitial positions through the oxide phase.

Because of different characteristics of the ceramic phases, sintering of composites formed by an oxide and nitrides (or carbides) usually require high temperature and specific techniques both to avoid chemical modification of the phases and to promote high densification. Previous studies have significantly advanced the processing of such ceramic composites $[21,23,30,31,32,33,34]$. To form stabilized $-\mathrm{ZrO}_{2} / \mathrm{TiN}$ composites whilst avoiding the TiN chemical oxidation, samples were consolidated by field assisted sintering, i.e. by spark plasma sintering (SPS) [21,23,30,31]. The SPS allows fast densification in short time by imposing high electric current under inert atmosphere during the compacting process at high temperatures [32]. Such sintering process usually results in samples with high density and reduced grain sizes as compared to those of samples produced by standard sintering. Thus, to further advance such composites it is important to define both the temperature and the oxygen partial pressure conditions in which the outstanding properties of YSZ/TiN can be advantageous. The oxidation of TiN imposes an enormous challenge for 
electrochemical applications at high temperature that rely on the MIEC properties of YSZ/TiN composites.

In this study, we explored both the potential and limits of YSZ/TiN composites at high temperatures as possible candidates for electrochemical applications, e.g. porous electrodes in solid oxide fuel cells (SOFCs), electrochemical sensors, and dense oxygen gas transport membrane (OTM). Changes observed in both thermal and electrical properties, investigated in oxidant and inert atmosphere, were associated with partial oxidation of titanium nitride.

\section{Experimental}

\section{Composite preparation}

Commercial powders were used as starting materials: i) $\mathrm{ZrO}_{2}: 8 \mathrm{~mol} \% \mathrm{Y}_{2} \mathrm{O}_{3}$ (YSZ, Tosoh, Japan), average particle size $4 \mu \mathrm{m}$ and ii) TiN (Sigma-Aldrich) average particle size $3 \mu \mathrm{m}$. YSZ / $x$ TiN composites were prepared in batches of $5 \mathrm{~g}$, in the following weight fractions: $x=0,25,50$, and 75 wt.\% TiN, corresponding to volumetric fractions of $\mathrm{v}=0,27.7,53.4$, and 77.5 vol. $\%$ TiN [35]. Powders were mixed in stainless steel cups with zirconia milling balls (4 mm diameter) and 5 $\mathrm{ml}$ of ethanol using a Fritsch mill Pulverisette 7. Mixing was carried out in 4 cycles, at $500 \mathrm{rpm}$ for 5 min and 10 min pause between each cycle, with a total effective 20 min mixing time. The mixed powders were sieved to remove the grinding media, dried at $120{ }^{\circ} \mathrm{C}$ under stirring, and finally homogenized in an agate mortar for $\sim 15 \mathrm{~min}$.

Zirconia-based samples with addition of TiN having high density and high electrical conductivity, usually require advanced sintering techniques such as hot pressing and SPS [33,34]. Compared to the conventional process, the SPS sintering allows achieving high densities at lower 
temperatures and times, inhibits unwanted reactions, and promotes densification with small grain growth [33,34]. Samples YSZ / $x$ TiN were sintered by SPS (SPS 1050 Dr. Sinter Syntex, Inc.) at $1450{ }^{\circ} \mathrm{C}$ for $5 \mathrm{~min}$ with a heating rate of $100{ }^{\circ} \mathrm{C} \mathrm{min}^{-1}, 0.1 \mathrm{Torr}$, and $3.7 \mathrm{kN} / \mathrm{cm}^{2}$ charging load during heating, then held at constant charging load of $9.3 \mathrm{kN} / \mathrm{cm}^{2}$ when temperature reached 1450 ${ }^{\circ} \mathrm{C}$ [35]. The composite powder was inserted into a graphite die/punches set (2 inches diameter). The samples were isolated from punches and matrix wall with a graphite foil $\sim 0.4 \mathrm{~mm}$ thick to prevent direct contact with the die and punches. In each SPS run two samples were sintered simultaneously by positioning one over the other, with a graphite separator (1.5 $\mathrm{mm}$ thickness) inserted between the samples. Typical sample dimensions after SPS were $\sim 14 \mathrm{~mm}$ diameter and 1 mm thickness.

Carbon contamination is usually observed in samples fabricated by SPS. Typically, such contamination is easily eliminated by heat treatments at $\sim 900{ }^{\circ} \mathrm{C}$ in oxidizing atmosphere. However, in the present study the temperature required for carbon oxidation was higher than that for TiN oxidation. Thus, to preserve the composites after SPS and remove carbon residues, samples were rectified in a diamond wheel that removed $\sim 300 \mu \mathrm{m}$ from each parallel surface of the samples [35].

\section{Composite characterization}

Phase identification was monitored by X-ray diffractometry (XRD) in a Rigaku (MinifFlex) X-ray diffractometer operating at $30 \mathrm{kV}$ and $15 \mathrm{~mA}$. X-rays diffraction patterns of sintered samples were collected in the $20^{\circ}-90^{\circ} 2 \theta$ range, with step size $0.05^{\circ}$ and 2 s counting time, using $\mathrm{Cu} \mathrm{K}_{\alpha}$

radiation $(\lambda=1.5406 \AA)$. Simultaneous thermogravimetric and differential scanning calorimetry (TG/DTA) analyses were used for studying the composite stability in different atmosphere. Composite powders and fragments cut from sintered samples were analyzed by TG/DTA runs under 


\section{ACCEPTED MANUSCRIPT}

air (oxidative) or Argon (inert) flow $\left(50 \mathrm{mLmin}^{-1}\right)$ with $10{ }^{\circ} \mathrm{C} \mathrm{min}^{-1}$ heating rate in a Setaram Labsys apparatus. The microstructure of sintered composite samples was investigated by scanning electron microscopy (SEM, JEOL Model JSM 6010-LA). For SEM analyses, bulk fragments were cut from sintered samples, immobilized in epoxy resin and polished in diamond paste down to diamond average particle size of $1 \mu \mathrm{m}$. Bar-shaped samples, cut from cylindrical pellets, with $\mathrm{Pt}$ contact pads cured at $100{ }^{\circ} \mathrm{C}$, were used for electrical resistance measurements in both static air and Ar flow $\left(\mathrm{pO}_{2} \sim 10^{-5} \mathrm{~atm}\right)$ [36,37]. Electrical resistance measurements were performed using a Lakeshore 370 resistance bridge and a house made 4-probe alumina sample holder with Pt contact leads, from room temperature up to $800{ }^{\circ} \mathrm{C}$ during heating and cooling $\left( \pm 3{ }^{\circ} \mathrm{C} \mathrm{min}{ }^{-1}\right)$. A digital multimeter (Keithley 2000) monitored the temperature measured by a type-K thermocouple positioned close to the sample. Resistance and temperature data were automatically collected using a homemade LabView software.

\section{Results and discussion}

The SPS process at $1450{ }^{\circ} \mathrm{C}$ resulted in high densification (> 95\% of the theoretical density) regardless the composite composition. Such sintering temperature is lower than the typical ones used for sintering TiN-based materials using vacuum sintering or hot-pressing techniques [38-40]. Figure 1 shows images of cold fractured surface of sample YSZ/50TiN with the corresponding EDX spectra of the different phases. Phase contrast due the different materials properties allowed easy identification of isolated dark and bright particles that were associated with TiN and YSZ, respectively. Elemental analysis confirmed the phase contrast of phases in the composite sample. 


\section{ACCEPTED MANUSCRIPT}
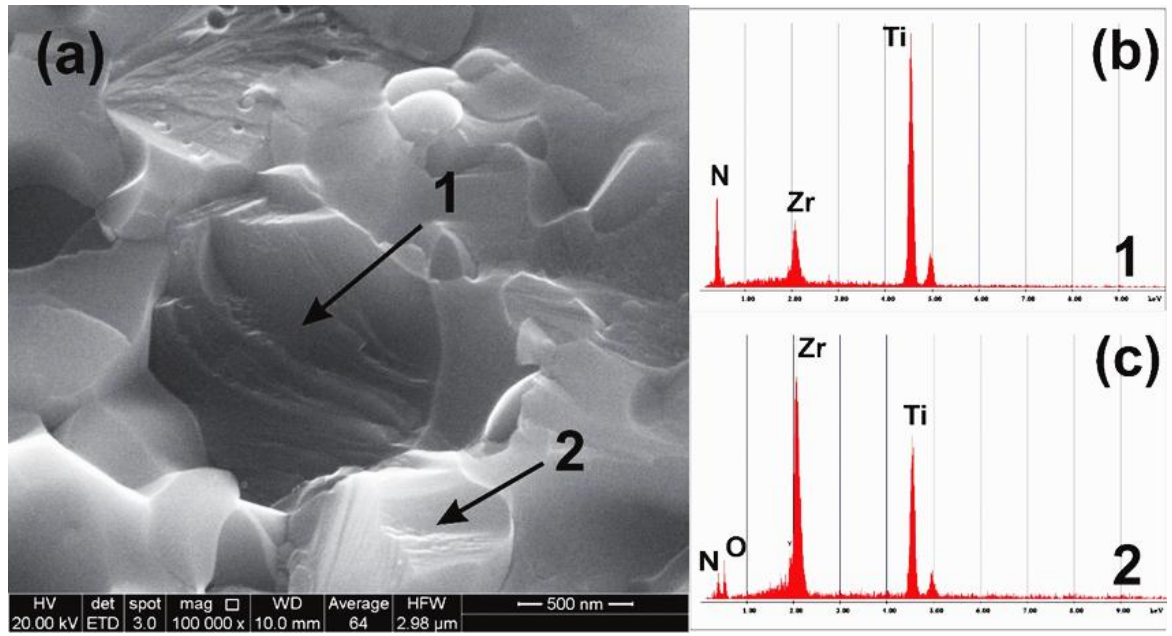

Figure 1: a) SEM image of fractured surface of YSZ/50TiN with corresponding EDX spectra for two different grains marked as 1 and 2. (b) for Ti-rich grains (1) and (c) for Zr-rich grains (2).

Figure 2 (a-c) shows SEM images of the polished surfaces of YSZ/xTiN samples at different magnifications. Both the oxide and nitride phases are well dispersed and homogenously distributed in the composite. 


\section{ACCEPTED MANUSCRIPT}

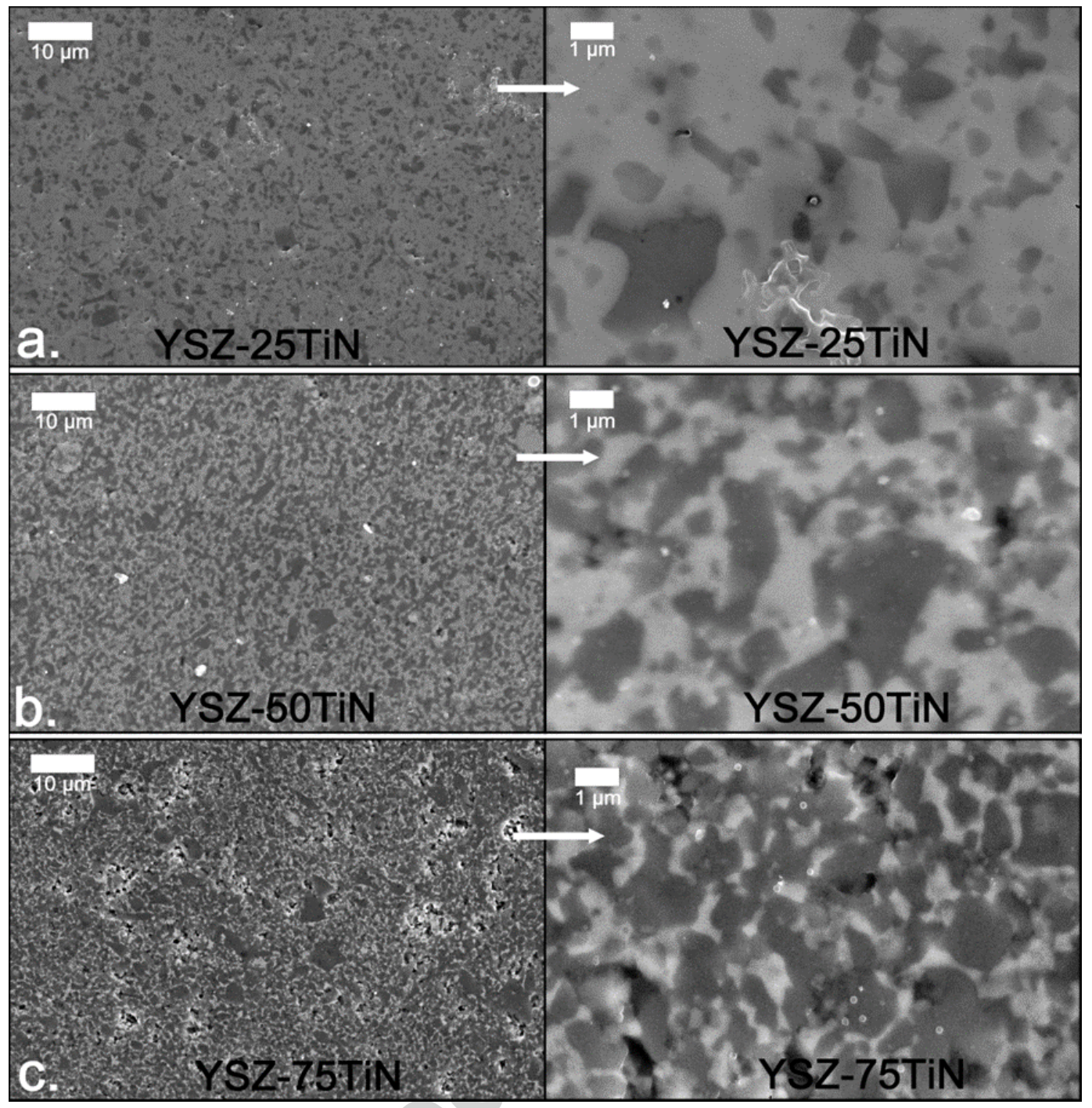

Figure 2: SEM images of polished surfaces of YSZ/xTiN composites with $x=25,50$, and 75

wt.\%. Right side images correspond to higher magnification images of left side images.

The SEM images of polished bulk surfaces revealed clean interfaces between oxide and nitride with no additional phases, which could result have resulted from both undesired reactions between phases or nitride decomposition. Detailed SEM analyses revealed that YSZ/25TiN and YSZ/50TiN samples are nearly fully dense, whereas samples with higher amounts of nitride, such as YSZ/75TiN, exhibited low residual porosity. Similar trend of the apparent density was 


\section{ACCEPTED MANUSCRIPT}

previously observed in such composites [20,24]. Such an effect is attributed to the high concentration of TiN, which is difficult to be densified and inhibits the densification of the composite. Phase contrast in SEM images evidences that TiN grains have an irregular shape with a broad size distribution, with clusters sizes ranging from submicron size to $\sim 3 \mu \mathrm{m}$ in YSZ/25TiN sample. Increasing the volume fraction of TiN results in larger TiN particles as observed for samples with $x=50$ and $75 \mathrm{wt} . \%$ TiN. Average grain size were calculated from high magnification images of Fig. 1 and the results obtained were $\sim 0.68 \mu \mathrm{m}, 0.95$ and $1.0 \mu \mathrm{m}$ for samples $x=25$, 50, and $75 \%$, respectively.

The XRD patterns of the samples after SPS were reported elsewhere [35]. The diffraction patterns indicate coexistence of the zirconium oxide and titanium nitride phases in the whole range of relative compositions. No additional phases, segregation, or $\mathrm{TiO}_{2}$ were detected in the composite SPS samples. Lattice parameters calculated from XRD are shown in Table 1 along with apparent densities measured by Archimedes method. The calculated values of lattice parameters are close to the ones expected for each phase and no significant dependence of lattice parameters on the composite relative composition was observed. Such results strongly indicate that no reaction between the phases occurred. Measured apparent densities confirmed that SPS composites achieved high density, as observed in SEM analysis (Fig. 2). Apparent densities values reflect the increased porosity with increasing TiN volume fraction observed in SEM images. 


\section{ACCEPTED MANUSCRIPT}

Table 1: Lattice parameters and density for YSZ/TiN composites. $d_{T}$ is the theoretical composite density calculated by the rule of mixtures using $d_{Y S Z}=6.02 \mathrm{gcm}^{-3}$ and $d_{T i N}=5.24$ $\mathrm{gcm}^{-3}$

\begin{tabular}{cccccc}
\hline Sample & $\boldsymbol{a}$ TiN & $\boldsymbol{a}$ YSZ & $\boldsymbol{d}$ & $\boldsymbol{d}_{\mathrm{T}}$ & $\boldsymbol{d} / \boldsymbol{d}_{\mathrm{T}}$ \\
& $(\mathbf{n m})$ & $(\mathbf{n m})$ & $\left(\mathbf{g . c m}^{-\mathbf{3}}\right)$ & $\left(\mathbf{g . c m}^{-\mathbf{3}}\right)$ & $(\%)$ \\
\hline YSZ/25TiN & 0.4240 & 0.5130 & 5.7 & 5.80 & 98 \\
YSZ/50TiN & 0.4241 & 0.5134 & 5.3 & 5.60 & 95 \\
YSZ/75TiN & 0.4244 & 0.5137 & 5.2 & 5.42 & 96 \\
\hline
\end{tabular}

The oxidation of $\mathrm{TiN}$ to $\mathrm{TiO}_{2}$ is a well-known reaction, which is usually activated at $\mathrm{T}>600$ ${ }^{\circ} \mathrm{C}$ in air $[28,29]$. In atmospheres other than air, with $\mathrm{pO}_{2}<0.21$ atm, the reactivity of TiN is less known [29]. Since the TiN oxidation is activated at the surface, the reactivity of the TiN embedded in the dense $\mathrm{YZ}$ composite matrix may be affected by the formation of protective $\mathrm{TiO}_{2}$ layers. Figures $3 \mathrm{a}$ and $3 \mathrm{~b}$ show TG/DTA data of dense fragments of SPS samples in air $\left(\mathrm{pO}_{2}=0.21 \mathrm{~atm}\right)$ and Ar flow ( $\left.\mathrm{pO}_{2} \sim 10^{-5} \mathrm{~atm}\right)$, respectively. Thermal analyses data show the evolution of the mass as function of the temperature (TG) indicating the thermal character of the reactivity of composite samples in different gases. 

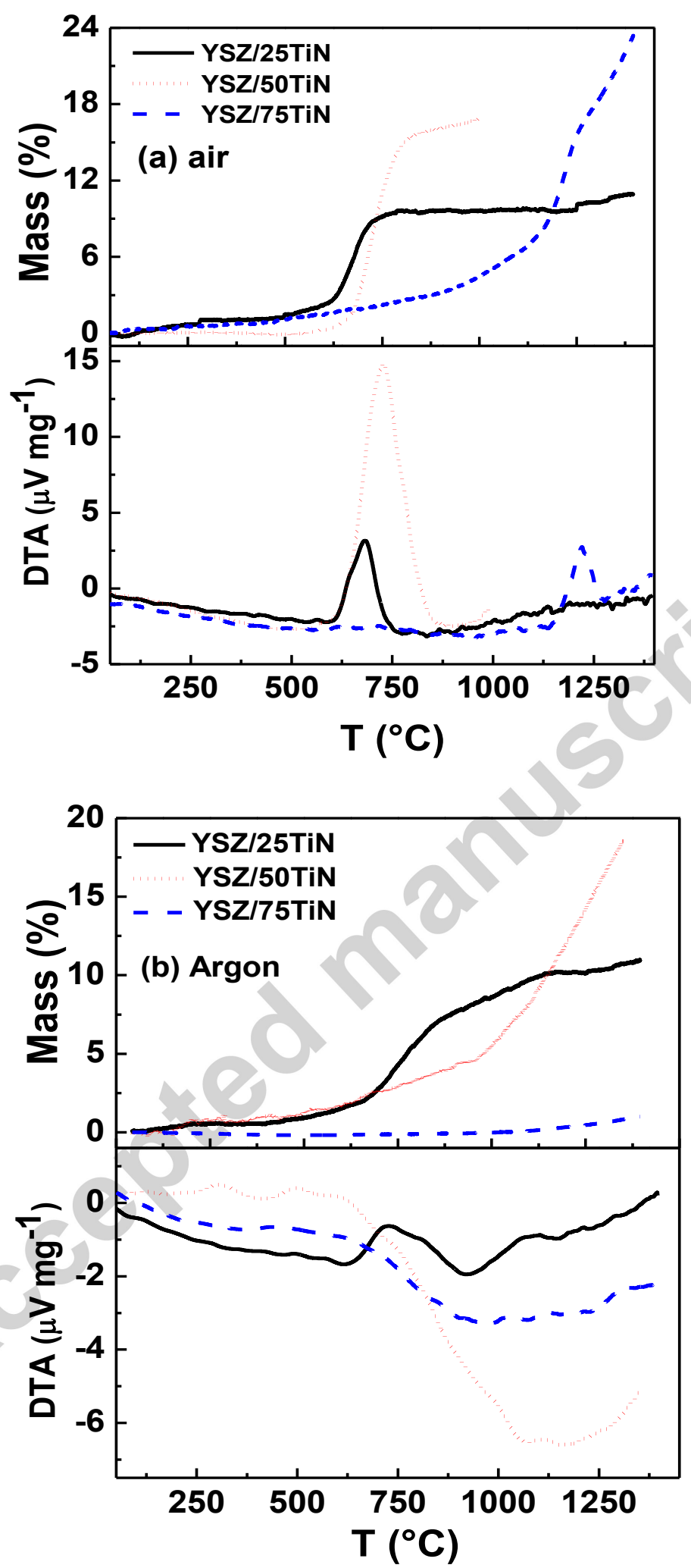

Figure 3: TG/DTA curves of SPS YSZ/TiN composites in air (a) and in Argon (b) flow [35]. 
In air, the sample $x=25 \mathrm{wt} \%$ exhibits a mass uptake event in the $500-800^{\circ} \mathrm{C}$ temperature range, associated with an exothermic peak at $\sim 730^{\circ} \mathrm{C}$ due the oxidation of TiN. The expected total mass uptake from the oxidation reaction of $\mathrm{TiN}$ for the YSZ/25TiN composite is $7.5 \%$, and the calculated value from TG data is $\sim 8 \%$. Therefore, the observed mass uptake value is in agreement with the stoichiometry of the composite and suggest that oxidation of TiN was complete. For the sample $x=50 \mathrm{wt} \%$, similar features were observed. The exothermic peak was practically unchanged at $730{ }^{\circ} \mathrm{C}$ and the mass uptake onset was shifted to $\sim 560{ }^{\circ} \mathrm{C}$, with a total mass uptake of $\sim 17 \%$ up to $1000{ }^{\circ} \mathrm{C}$. Such a mass uptake is also in agreement with the theoretical value expected for the $x=50 \%$ nominal composition $(16 \%)$. However, further increasing the TiN content changes the oxidation behavior of the composite. The sample YSZ/75TiN has a higher onset for the mass uptake $\left(\sim 580{ }^{\circ} \mathrm{C}\right)$ due to TiN oxidation, as compared to other samples. The associated exothermic peak was shifted to $\sim 1220{ }^{\circ} \mathrm{C}$ and the mass uptake develops over the entire temperature range investigated with a total mass uptake of $\sim 21 \%$ up to $1400{ }^{\circ} \mathrm{C}$, a value very close to the theoretical one (22\%). The resistance towards oxidative treatments was further investigated by TG/DTA analyses under Ar flow ( $\mathrm{pO}_{2} \sim 10^{-5} \mathrm{~atm}$ ), as shown in Fig. 3b. For the sample YSZ/25TiN, the onset of oxidation was $\sim 500{ }^{\circ} \mathrm{C}$, similarly to TG data collected in air, but mass uptake developed over a larger temperature range up to $\sim 1200^{\circ} \mathrm{C}$. The total mass uptake was comparable to the one measured in air, indicating total oxidation of the TiN phase. Nevertheless, the most significant change was observed for YSZ/75TiN in which mass uptake $(\sim 1 \%)$ was practically inhibited and the exothermic peak was not clearly discerned up to $1400{ }^{\circ} \mathrm{C}$.

Thermal analysis data showed a strong dependence on the microstructure of the composite. It is worthy of mentioning that the TG data (not shown) for the starting TiN powder showed an oxidative behavior comparable to that of SPS composite sample with $x=25 \mathrm{wt} . \%$, in both air and 
Ar flow [35]. The main difference is that exothermic peak of the TiN powder was identified at lower temperature $\left(660^{\circ} \mathrm{C}\right)$ than that of the SPS composite samples. Therefore, the oxidation of dense composites with high volume fraction $(x=50$ and 75 wt.\%) of TiN was affected by the composite microstructure. In composite samples both the high density and the presence of the YSZ phase inhibited the oxidation of TiN. Such a feature is probably related to a decreased oxygen diffusion rate through the less accessible bulk of TiN particles in the high-density composite media. Mass increases as result of $\mathrm{N}_{2}$ release and $\mathrm{O}_{2}$ sorption in oxidative conditions. The TG/DTA analyses on SPS composites indicated an increase in mass upon oxidation and a shift to higher temperature of the exothermic peak associated with the TiN oxidation that correlates with $x$, i.e., the higher the TiN volume fraction, further the exothermic peak shifts towards higher temperatures. Such effects of the TiN volume fraction dependence of the thermal properties were significantly greater in Ar flow $\left(\right.$ low $\mathrm{pO}_{2}$ ). In summary, TG/DTA analyses show a substantial stability of the composites up to $600{ }^{\circ} \mathrm{C}$ with a partial oxidation that depends on the amount of the TiN phase in the composite and the oxygen partial pressure.

Figure 4 shows the temperature dependence of the electrical resistivity of YSZ/TiN composites under Ar flow $\left(\mathrm{pO}_{2} \sim 10^{-5} \mathrm{~atm}\right)$. 

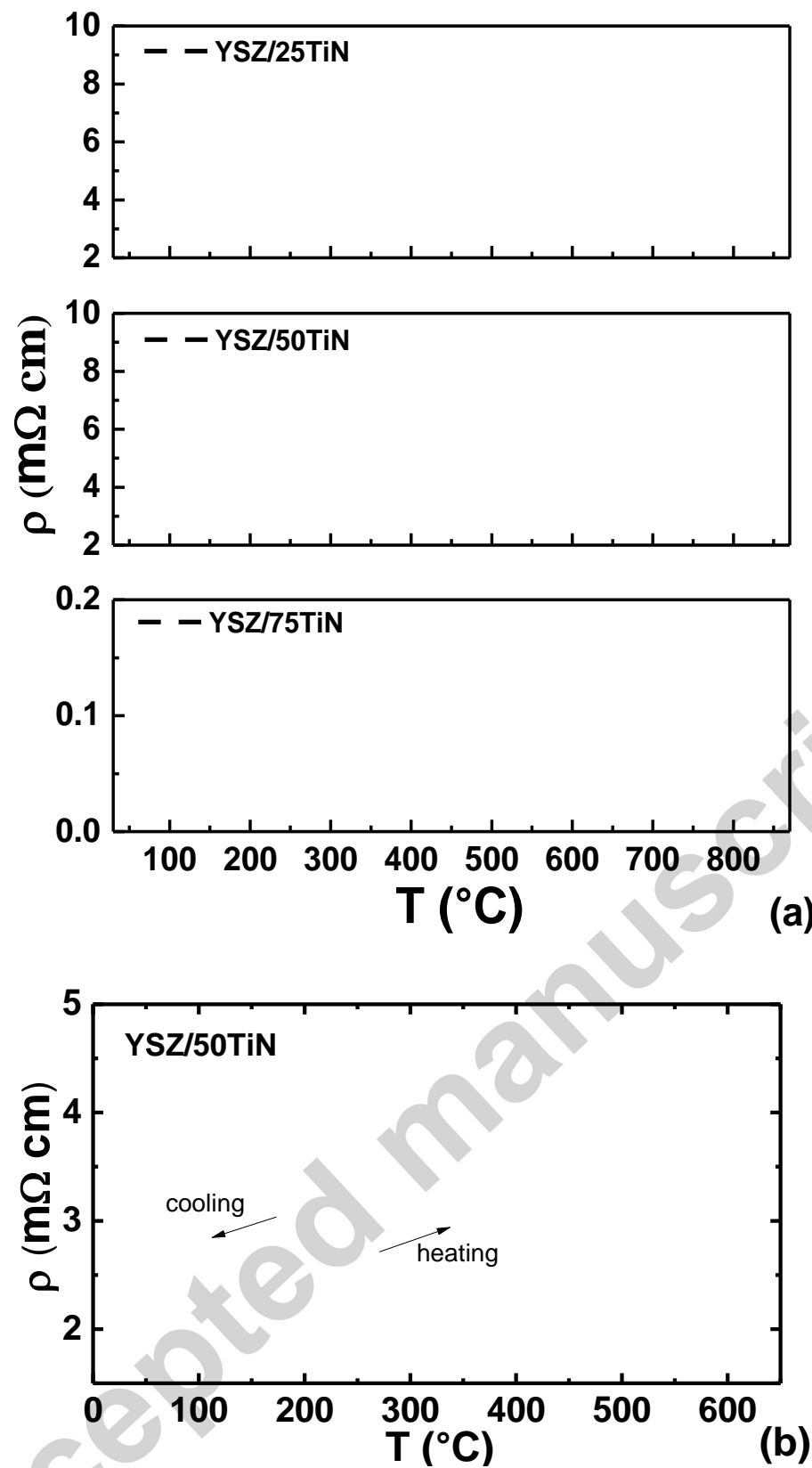

Figure 4: Temperature dependence of the electrical resistivity of SPS YSZ/TiN composites in Ar flow: (a) measurements corresponding to the first heating of freshly SPS samples up to 800 ${ }^{\circ} \mathrm{C}$; (b) stability of the resistivity of sample YSZ/50 TiN upon heating up to $600{ }^{\circ} \mathrm{C}[35]$.

A first result evident from Fig. 4 is the electronic character of the electrical resistivity of composite samples, i.e., resistivity increases with increasing temperature. Both the magnitude and 


\section{ACCEPTED MANUSCRIPT}

the temperature dependence of the electrical resistivity of all samples, including the one with the lowest TiN volume fraction $x=25$ wt. $\%$, i.e. 27 vol. $\%$, exhibited features of the transport properties associated with the nitride phase. The results indicate that samples reached the percolation threshold for the TiN at volumetric fractions below the standard percolation threshold of 33 vol.\% [41]. Such an effect is probably related to the microstructural features resulting from both the powder processing and the SPS, which promoted the formation of homogeneous and high-density composites. Fig. 4a shows that increasing TiN fraction decreased the electrical resistivity of the composite while increasing the temperature increases resistivity, a feature that was more pronounced in samples YSZ/75TiN above $700{ }^{\circ} \mathrm{C}$. It is worth mentioning that all samples showed an increased resistivity upon cooling from $800{ }^{\circ} \mathrm{C}$. According to the thermal analysis such an increase of the resistivity could be related to a superficial oxidation of TiN. Therefore, we have investigated the stability of the resistivity in a lower temperature range (up to $600{ }^{\circ} \mathrm{C}$ ) as shown in Fig. 4b. Limiting the maximum temperature to $600{ }^{\circ} \mathrm{C}$ under $\mathrm{Ar}$ resulted in no significant change in the magnitude of the resistivity of the sample YSZ/50TiN. 

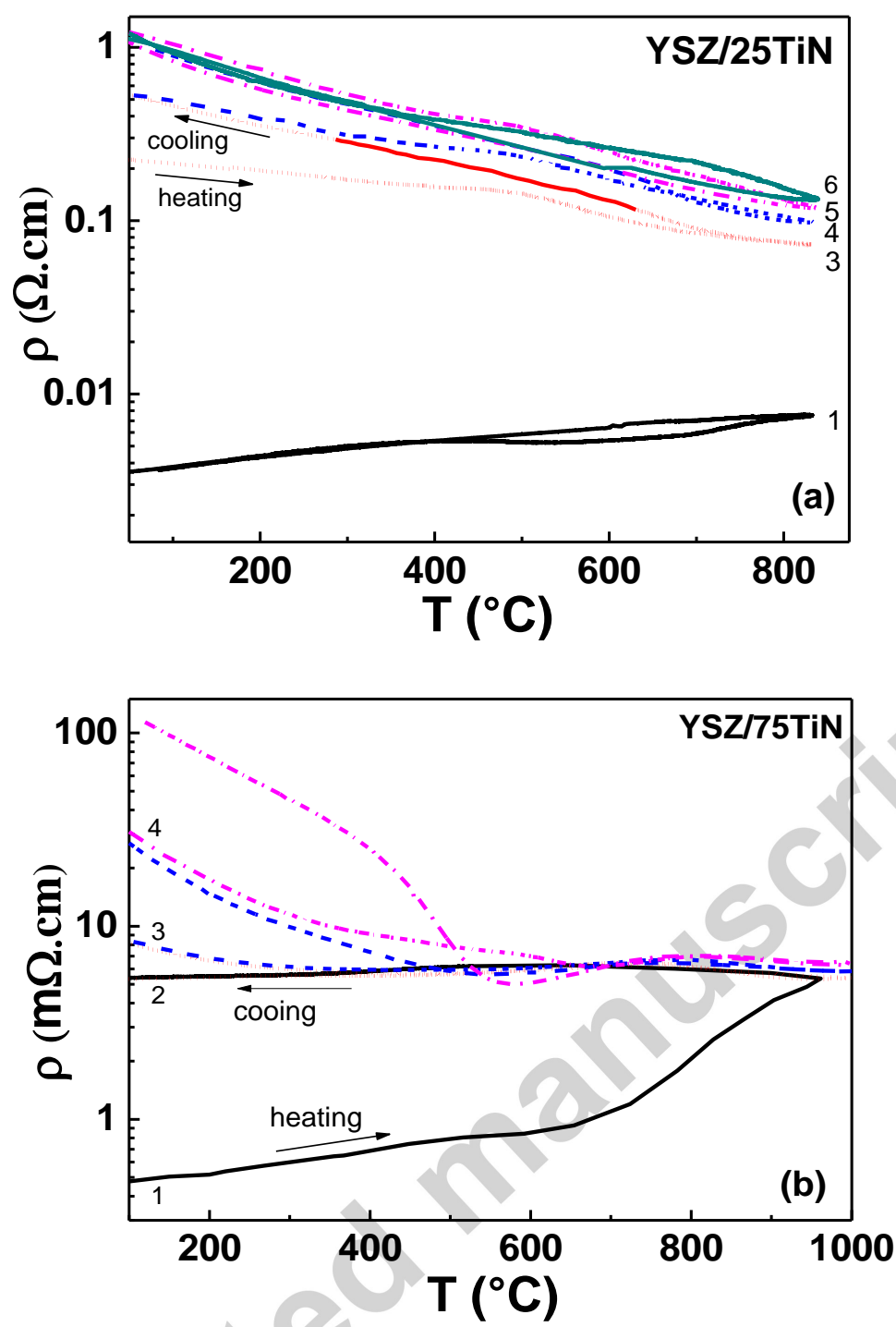

Figure 5: Temperature dependence of the electrical resistivity of SPS YSZ/TiN composites in Ar flow: (a) measurements corresponding to the first heating of freshly SPS samples up to 800 ${ }^{\circ} \mathrm{C}$; (b) stability of the resistivity of sample YSZ/50 TiN upon heating up to $600{ }^{\circ} \mathrm{C}$. Numbers indicate the number of the heating/cooling run.

Electrical resistivity measurements were carried out to evaluate the effect of the TiN oxidation to $\mathrm{TiO}_{2}$ in the composites at high temperatures. Figure 5 shows 4-probe dc electrical resistivity data collected during sequential heating/cooling $(h / c)$ runs for samples $x=25$ and 75 wt. $\%$ 
in air. Interestingly, the chemical evolution of the sample led to non-linear rise in the electrical resistivity at high temperatures. Starting from the $2^{\text {nd }} h / c$ run the resistivity increased at lower temperatures, indicating a dominant semiconductor character in the samples. Measurements clearly show a progressive increase of the resistivity upon the number of $h / c$ runs in perfect agreement with the TG/DTA data. However, samples with different TiN volume fractions exhibit different trends. For sample $x=25 \mathrm{wt} . \%$ the first $h / c$ run shows a rather good stability, but increasing the number of heating cycles rapidly increases the resistivity and changes the electronic behavior to a semiconducting behavior, i.e., the resistivity decreases with increasing measuring temperature from the $3^{\text {rd }} h / c$ run onwards. Further increasing the number of $h / c$ runs apparently stabilizes (or completes) the oxidation of $\mathrm{TiN}$ and the sample shows a semiconducting behavior with no significant variation of the magnitude of electrical resistivity for subsequent runs $\left(5^{\text {th }}\right.$ and $6^{\text {th }} h / c$ runs). At high temperature $\left(600<\mathrm{T}\left({ }^{\circ} \mathrm{C}\right)<800\right)$, in both $5^{\text {th }}$ and $6^{\text {th }}$ runs, the YSZ/25 TiN sample exhibits a thermally activated behavior with calculated activation energy of $\sim 0.17 \mathrm{eV}$. Such a relatively low value indicates that the electrical transport in the samples is dominated by the semiconducting titanium phases (nitride and rutile) rather than YSZ oxygen conducting phase, which has activation energies much higher than that (typically, $\sim 1 \mathrm{eV}$ ). For the sample $x=75 \mathrm{wt} \%$ increasing the number of measurements under $h / c$ runs has a marked effect at low measuring temperatures $\left(<600^{\circ} \mathrm{C}\right)$. As compared to the $1^{\text {st }}$ heating, a significant increase of the resistivity is observed during cooling of the $1^{\text {st }} \mathrm{h} / \mathrm{c}$ run. It is worth to note that sample YSZ/75TiN shows a practically temperature-independent electrical behavior during the $1^{\text {st }}$ cooling, a feature confirmed by the nearly coincident data measured during the heating of the $2^{\text {nd }} h / c$ run. However, further increasing the number of $h / c$ runs at high temperature promotes the change to a semiconducting behavior with a pronounced increase of the resistivity at low temperature. However, the resistivity 
at high temperature $\left(>600{ }^{\circ} \mathrm{C}\right)$ is considerably less dependent of the number of $h / c$ runs. Further increasing the number of $h / c$ runs resulted in mechanical failure of the sample.

The results in Figures 4 and 5 show that the electrical properties of such ceramic composites, formed by an ionic conductor and an electronic nitride phase, can be tuned for applications that require different types of electrical properties. By adjusting both the relative volume fraction of phases and the controlled oxidation of the nitride (electronic) phase in the composite it is possible to obtain different types of effective charge transport, including a temperature-independent resistivity material with relatively low resistivity $(\sim 10 \mathrm{~m} \Omega \mathrm{cm})$, a thermally-activated semiconductor, and electronic conductor. Moreover, Figs. 4 and 5 indicate that such tunable composites can have a rather broad range of temperature, from room temperature up to $\sim 500{ }^{\circ} \mathrm{C}$, in which they can operate with good stability.

Figure 6 shows XRD after oxidation and thermal treatments in air. The diffraction patterns clearly indicate the formation of $\mathrm{TiO}_{2}$ phase in the composite samples. The XRD data confirmed that the observed change in the electrical properties of the composite SPS samples is associated with the progressive oxidation of the nitride phase upon heat treatment at high temperature and controlled $\mathrm{pO}_{2}$. After cycling at high temperature, samples exhibit coexisting phases of YSZ, TiN and rutile. Such result shows that samples were not completely oxidized during the experiments, confirming the protective effect of the dense microstructure of the composite against full oxidation of TiN, in agreement with the thermal analyses. Despite the partial oxidation of TiN in the dense sample, $\mathrm{TiO}_{2}$ is a semiconductor and its presence in the materials may be tolerated for certain applications. Interestingly, the coincident diffraction peaks suggest that no significant variation of 
lattice parameters occurred, indicating no reaction between the phases of the composite during the controlled oxidative treatment.
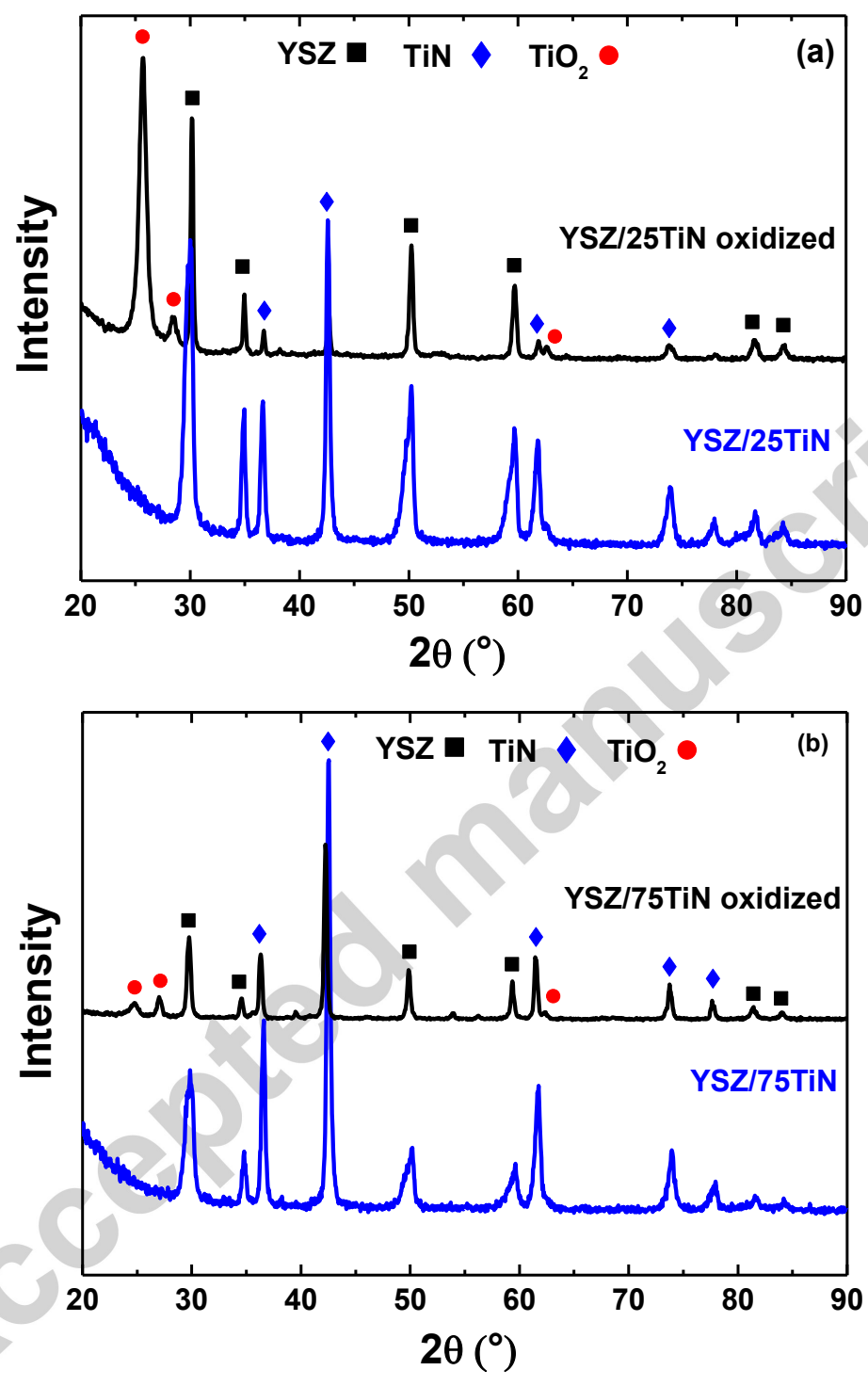

Figure 6: X-rays diffraction patterns of SPS YSZ/TiN composites. YSZ/75TiN-f stands for the sample sintered in conventional furnace under Ar flow. Indexed peaks correspond to YSZ

$(\diamond), \operatorname{TiN}(\bullet)$, and $\mathrm{TiO}_{2}$-rutile $(*)$. 


\section{Conclusions}

Ceramic composite YSZ/TiN were fabricated by spark plasma sintering. Composite samples exhibited high bulk densities ( $\geq 96 \%$ of theoretical density), homogeneous phase distribution, and no reaction between the components or oxidation of the TiN. Composites sintered by SPS showed electrical properties that resemble those of $\mathrm{TiN}$, with metallic behavior, reflecting the $\mathrm{TiN}$ percolation in the zirconia matrix. It was observed that the thermal and electrical properties of the composites are strongly dependent on the partial pressure of oxygen and temperature. Even under argon flow at relatively low partial pressures of oxygen $(\sim 10 \mathrm{ppm})$, the composite properties are strongly affected by the oxidation of $\mathrm{TiN}$ to $\mathrm{TiO}_{2}$, which occurs at temperatures above $500{ }^{\circ} \mathrm{C}$. The thermal analysis showed that the microstructure of a composite TiN inhibited the oxidation kinetics. The oxidation of TiN was followed by electrical resistivity measurements in consecutive heatingcooling runs showing the change of the composite transport properties by the resulting nitride oxidation. The results demonstrated that the electrical properties of ceramic composites composed by phases with distinct charge carriers can be combined and tuned by controlled oxidation thermal treatments.

\section{Acknowledgements}

Authors are thankful for the financial support of Brazilian agencies CNEN, CNPq (447813/2014-5 and 401218/2014-7), and Fapesp (2015/20434-0, 2014/09087-4 and 2014/50279-4). FCF and DZF are CNPq fellows. 


\section{References}

[1] A. Smirnov, J. Beltran, T. Rodriguez-Suarez, C. Pecharroman, M.C. Muñoz, J. Moya, J. Bartolomé, Unprecedented simultaneous enhancement in damage tolerance and fatigue resistance of zirconia/Ta composites, 2017. doi:10.1038/srep44922.

[2] H. Sun, B.S. Dunn, Y. Huang, X. Duan, Three-Dimensional Holey-Graphene/Niobia Composite Architectures for Ultrahigh-Rate Energy Storage, Meet. Abstr. . MA2017-02 (2017) 109.

[3] P. Gao, S. Li, X. Bu, S. Dang, Z. Liu, H. Wang, L. Zhong, M. Qiu, C. Yang, J. Cai, W. Wei, Y. Sun, Direct conversion of $\mathrm{CO} 2$ into liquid fuels with high selectivity over a bifunctional catalyst, Nat Chem. advance on (2017).

[4] A.L. Moore, L. Shi, Emerging challenges and materials for thermal management of electronics, Mater. Today. 17 (2014) 163-174. doi:https://doi.org/10.1016/j.mattod.2014.04.003.

[5] M. Shahedi Asl, I. Farahbakhsh, B. Nayebi, Characteristics of multi-walled carbon nanotube toughened ZrB2SiC ceramic composite prepared by hot pressing, Ceram. Int. 42 (2016) 1950-1958. doi:https://doi.org/10.1016/j.ceramint.2015.09.165.

[6] Y. Wu, C. Xia, W. Zhang, X. Yang, Z.Y. Bao, J.J. Li, B. Zhu, Natural Hematite for Next-Generation Solid Oxide Fuel Cells, Adv. Funct. Mater. 26 (2016) 938-942. doi:10.1002/adfm.201503756.

[7] J. Myung, S.-D. Kim, T.H. Shin, D. Lee, J.T.S. Irvine, J. Moon, S.-H. Hyun, Nano-composite structural Ni-Sn alloy anodes for high performance and durability of direct methane-fueled SOFCs, J. Mater. Chem. A. 3 (2015) 13801-13806. doi:10.1039/C4TA06037G.

[8] R. Stadelmann, M. Lugovy, N. Orlovskaya, P. Mchaffey, M. Radovic, V. Sglavo, S. Grasso, M.J. Reece, Mechanical Properties and Residual Stresses in ZrB2-SiC Spark Plasma Sintered Ceramic Composites, 2016. 


\section{ACCEPTED MANUSCRIPT}

doi:10.1016/j.jeurceramsoc.2016.01.009.

[9] F.C. Fonseca, R. Muccillo, Impedance spectroscopy of (yttria-stabilized zirconia)-magnesia ceramic composites, Solid State Ionics. 131 (2000). doi:10.1016/S0167-2738(00)00683-4.

[10] V. Esposito, D.W. Ni, D. Marani, F. Teocoli, K.T. Sune Thydén, D.Z. De Florio, F.C. Fonseca, Accelerated ceria-zirconia solubilization by cationic diffusion inversion at low oxygen activity, J. Mater. Chem. A. 4 (2016) 16871-16878. doi:10.1039/C6TA06308J.

[11] A. Datye, K.-H. Wu, G. Gomes, V. Monroy, H.-T. Lin, J. Vleugels, K. Vanmeensel, Synthesis, microstructure and mechanical properties of Yttria Stabilized Zirconia (3YTZP) - Multi-Walled Nanotube (MWNTs) nanocomposite by direct in-situ growth of MWNTs on Zirconia particles, Compos. Sci. Technol. 70 (2010) 2086-2092. doi:10.1016/j.compscitech.2010.08.005.

[12] J.J. Gengler, C. Muratore, A.K. Roy, J. Hu, A.A. Voevodin, S. Roy, J.R. Gord, Yttria-stabilized zirconia-based composites with adaptive thermal conductivity, Compos. Sci. Technol. 70 (2010) 2117-2122. doi:10.1016/j.compscitech.2010.08.010.

[13] X. Li, X. Wang, D. Liu, S. Song, H. Zhang, Multifunctional nanostructures based on porous silica covered Fe3O4@CeO2-Pt composites: a thermally stable and magnetically-recyclable catalyst system, Chem. Commun. 50 (2014) 7198-7201. doi:10.1039/C4CC01415D.

[14] J.M. Polfus, W. Xing, M.-L. Fontaine, C. Denonville, P.P. Henriksen, R. Bredesen, Hydrogen separation membranes based on dense ceramic composites in the La27W5O55.5-LaCrO3 system, J. Memb. Sci. 479 (2015) 39-45. doi:https://doi.org/10.1016/j.memsci.2015.01.027.

[15] W. Deibert, M. Ivanova, S. Baumann, O. Guillon, W. A. Meulenberg, Ion-Conducting Ceramic Membrane Reactors for High-Temperature Applications, J. Memb. Sci. 543 (2017). doi:10.1016/j.memsci.2017.08.016.

[16] S. Ran, L. Gao, Electrical properties and microstructural evolution of $\mathrm{ZrO} 2-\mathrm{Al} 2 \mathrm{O} 3-\mathrm{TiN}$ nanocomposites prepared by spark plasma sintering, Ceram. Int. 38 (2012) 4923-4928. doi:10.1016/j.ceramint.2012.02.084.

[17] Z. Guo, G. Blugan, R. Kirchner, M. Reece, T. Graule, J. Kuebler, Microstructure and electrical properties of Si3N4-TiN composites sintered by hot pressing and spark plasma sintering, Ceram. Int. 33 (2007) 1223-1229. 


\section{ACCEPTED MANUSCRIPT}

doi:https://doi.org/10.1016/j.ceramint.2006.03.029.

[18] J. Li, L. Gao, J. Guo, Mechanical properties and electrical conductivity of TiN-Al2O3 nanocomposites, J. Eur. Ceram. Soc. 23 (2003) 69-74. doi:https://doi.org/10.1016/S0955-2219(02)00089-4.

[19] C.-C. Liu, J.-L. Huang, Effect of the electrical discharge machining on strength and reliability of TiN/Si3N4 composites, Ceram. Int. 29 (2003) 679-687. doi:https://doi.org/10.1016/S0272-8842(02)00217-1.

[20] S. Salehi, O. Vander Biest, J. Vleugels, ZrO2-TiN Composites, Mater. Sci. Forum. 554 (2007) 135-140. doi:10.4028/www.scientific.net/MSF.554.135.

[21] K. Bonny, P. De Baets, J. Vleugels, A. Salehi, O. Van der Biest, B. Lauwers, W. Liu, Influence of secondary electro-conductive phases on the electrical discharge machinability and frictional behavior of $\mathrm{ZrO} 2$-based ceramic composites, J. Mater. Process. Technol. 208 (2008) 423-430. doi:10.1016/j.jmatprotec.2008.01.020.

[22] S. Salehi, O. Van der Biest, J. Vleugels, Electrically conductive ZrO2-TiN composites, J. Eur. Ceram. Soc. 26 (2006) 3173-3179.

[23] K. Vanmeensel, a. Laptev, O. Van der Biest, J. Vleugels, Field assisted sintering of electro-conductive ZrO2based composites, J. Eur. Ceram. Soc. 27 (2007) 979-985. doi:10.1016/j.jeurceramsoc.2006.04.142.

[24] K. Vanmeensel, A. Laptev, O. Van der Biest, J. Vleugels, The influence of percolation during pulsed electric current sintering of ZrO2-TiN powder compacts with varying TiN content, Acta Mater. 55 (2007) 1801-1811.

[25] F. Esaka, K. Furuya, H. Shimada, M. Imamura, N. Matsubayashi, H. Sato, A. Nishijima, A. Kawana, H. Ichimura, T. Kikuchi, Comparison of surface oxidation of titanium nitride and chromium nitride films studied by x-ray absorption and photoelectron spectroscopy, J. Vac. Sci. Technol. A Vacuum, Surfaces, Film. 15 (1997) 2521-2528. doi:10.1116/1.580764.

[26] G.N. Komratov, The oxidation kinetics of titanium carbide, nitride, and carbonitride powders in air, Powder Metall. Met. Ceram. 36 (1997) 510-514. doi:10.1007/BF02680504.

[27] N.C. Saha, H.G. Tompkins, Titanium nitride oxidation chemistry: An x- ray photoelectron spectroscopy study, J. Appl. Phys. 72 (1992) 3072-3079. doi:10.1063/1.351465. 


\section{ACCEPTED MANUSCRIPT}

[28] T.B. Ghosh, S. Dhabal, A.K. Datta, On crystallite size dependence of phase stability of nanocrystalline TiO2, J. Appl. Phys. 94 (2003) 4577-4582. doi:10.1063/1.1604966.

[29] X.-M. Hou, X.-J. Hu, K.-C. Chou, Kinetics of Thermal Oxidation of Titanium Nitride Powder at Different Oxidizing Atmospheres, J. Am. Ceram. Soc. 94 (2011) 570-575. doi:10.1111/j.1551-2916.2010.04084.x.

[30] P. Angerer, L.G. Yu, K.A. Khor, G. Krumpel, Spark-plasma-sintering (SPS) of nanostructured and submicron titanium oxide powders, Mater. Sci. Eng. A. 381 (2004) 16-19. doi:10.1016/j.msea.2004.02.009.

[31] J. Intrater, A Review of: "Sintering of Ceramics, M. N. Rahaman,” Mater. Manuf. Process. 23 (2007) 111-112. doi:10.1080/10426910701623956.

[32] D.A. Porter, K.E. Easterling, Phase Transformations in Metals and Alloys, Third Edition (Revised Reprint), Taylor \& Francis, 1992.

[33] J.E. Garay, Current-Activated, Pressure-Assisted Densification of Materials, Annu. Rev. Mater. Res. 40 (2010) 445-468. doi:10.1146/annurev-matsci-070909-104433.

[34] V. Mamedov, Spark plasma sintering as advanced PM sintering method, Powder Metall. 45 (2002) $322-328$. doi:10.1179/003258902225007041.

[35] Paulo S. M. Silva, F. C. Fonseca. Spark plasma sintering of yttria-stabilized zirconia/titanium nitride composites, Mater. Res. Soc. Symp. Proc. 1735 (2015) . doi: 10.1557/opl.2015.155.

[36] N.K. Monteiro, F.B. Noronha, L.O.O. da Costa, M. Linardi, F.C. Fonseca, A direct ethanol anode for solid oxide fuel cell based on a chromite-manganite with catalytic ruthenium nanoparticles. Int. J Hydrog. Energ. 37 (2012) 9816-9829. doi: 10.1016/j.ijhydene.2012.03.157

[37] F. C. Fonseca, E. N. S. Muccillo, R. Muccillo, and D. Z. de Florio, Synthesis and electrical characterization of the ceramic anode $\mathrm{La}_{1-\mathrm{x}} \mathrm{Sr}_{\mathrm{x}} \mathrm{Mn}_{0.5} \mathrm{Cr}_{0.5} \mathrm{O}_{3}$. J. Electrochem. Soc. 155 (2008) B483-B487. doi: 10.1149/1.2885099

[38] T. Rabe, R. Wäsche, Sintering behaviour of nanocrystalline titanium nitride powders, Nanostructured Mater. 6 (1995) 357-360. doi:https://doi.org/10.1016/0965-9773(95)00070-4.

[39] D.T. Castro, J.Y. Ying, Synthesis and sintering of nanocrystalline titanium nitride, Nanostructured Mater. 9 


\section{ACCEPTED MANUSCRIPT}

(1997) 67-70. doi:https://doi.org/10.1016/S0965-9773(97)00020-2.

[40] M.A. Kuzenkova, P.S. Kislyi, Vacuum sintering of titanium nitride, Sov. Powder Metall. Met. Ceram. 10 (1971) 125-128. doi:10.1007/BF00796410.

[41] F. C. Fonseca, R. Muccillo, D. Z. de Florio, L. O. Ladeira, A. S. Ferlauto, Mixed ionic-electronic conductivity in yttria-stabilized zirconia/carbon nanotube composites. Appl. Phys. Lett. 91 (2007) 243107. doi:

$10.1063 / 1.2821373$ 